\title{
Methotrexate dosage as a source of bias in biological trials in rheumatoid arthritis: a systematic review
}

\author{
Josefina Durán, ${ }^{1}$ Margarita Bockorny, ${ }^{2}$ Deepan Dalal, ${ }^{3}$ Michael LaValley, ${ }^{2}$ \\ David T Felson ${ }^{2,4}$
}

\begin{abstract}
Handling editor Tore K Kvien
- Additional material is published online only. To view please visit the journal online (http://dx.doi.org/10.1136/ annrheumdis-2016-209383)

${ }^{1}$ Rheumatology Department, School of Medicine, Pontificia Universidad Católica de Chile, Santiago, Chile

${ }^{2}$ Clinical Epidemiology Unit, Boston University School of

Medicine, Boston,

Massachusetts, USA

${ }^{3}$ Division of Rheumatology, Department of Medicine,

Brown University Warren Alpert School of Medicine,

Providence, Rhode Island, USA

${ }^{4}$ Arthritis Research UK Epidemiology Unit, Manchester NIHR Biomedical Research Unit, University of Manchester, Manchester, UK
\end{abstract}

\section{Correspondence to} Dr Josefina Durán, Rheumatology Department, School of Medicine, Pontificia Universidad Católica de Chile, Marcoleta 350, Santiago Centro, Santiago 8320000, Chile; jgduran@uc.cl

Received 15 February 2016 Revised 15 March 2016 Accepted 24 March 2016 Published Online First 18 April 2016

\footnotetext{
To cite: Durán J,

Bockorny M, Dalal D, et al. Ann Rheum Dis

2016;75:1595-1598.
}

\section{ABSTRACT}

Objectives To evaluate if optimal dose of either oral or injectable regimens of methotrexate (MTX) of $25 \mathrm{mg} /$ week was used in the comparator arms of studies comparing biologic drugs with MTX in rheumatoid arthritis (RA).

Methods A systematic literature search was carried out in MEDLINE, EMBASE and the Cochrane Library databases for randomised controlled trials comparing biologics with MTX in RA. A systematic review was performed among studies that met predefined criteria focusing on assessment of dose of MTX used in the comparator arm. Study authors were contacted when necessary. Study quality was assessed.

Results A total of 3276 references were identified and 13 trials were included. We obtained maximal dose and regimen for all. The maximal dose of MTX used in the comparator arm of the trials was no more than $20 \mathrm{mg} /$ week in any trial and for all but one trial, MTX was given orally and not by injection. The trial that used an injectable form reached a maximum of $15 \mathrm{mg} /$ week. Conclusions A suboptimal dose of MTX was used in biological clinical trials performed in RA, particularly regarding route of administration. This may have biased findings in favour of biological agents.

Numerous studies have demonstrated that studies sponsored by the manufacturing company are often more favourable to the sponsor's product compared with studies with other sources of sponsorship. One of the limitations in pharmaceuticalsponsored clinical trials is the use of a suboptimal dose of the comparator drug to provide an artefactual superiority for the investigational drug. ${ }^{1}$

Methotrexate (MTX) is the anchor drug in rheumatoid arthritis (RA). In trials conducted among Disease-Modifying Antirheumatic Drugs (DMARD) naïve patients with RA, trials have often compared MTX to biological agents and have reported superiority of biological treatment. No study, to our knowledge, has examined whether the dose of MTX used in such trials was optimal.

Evidence supports that the absorption of oral MTX is variable, when used at doses greater than $15 \mathrm{mg} /$ week and that injectable MTX at the higher doses reaches higher therapeutic levels ${ }^{2}$ and efficacy $^{3}$ than oral MTX. The European League against Rheumatism (EULAR) and expert opinion recommends up-titration of MTX up to $25 \mathrm{mg}$ / week for achieving disease control. ${ }^{45}$
Trials comparing biological agents with MTX serve as the basis for practice and for recommendations as to which treatments are efficacious. We carried out a systematic review of RA clinical trials to assess if optimal doses of MTX were used in the comparator arms of foundational trials comparing biological agents with MTX.

\section{METHODS}

\section{Research question}

We aimed to determine if MTX was used at its recommended dose in clinical trials evaluating the efficacy of biological drugs in RA. We reformulated the research question using the Population, Intervention, Comparison, Outcome, Study design (PICOS) method. Patients were subjects with RA; the intervention was a biological drug; the comparison was MTX; the outcome was clinical measurement of disease activity and the study design was randomised controlled trial (RCT).

\section{Systematic literature search}

A systematic literature search for articles published up to November 2014 was carried out in MEDLINE, EMBASE and the Cochrane Library, using the following search terms: rheumatoid arthritis, antitnf, anti tnf alpha, tumor necrosis factor alpha inhibitor, infliximab, cA2, remicade, adalimumab, D2E7, humira, etanercept, TNFR-Fc fusion protein, p75TNFR-FC, enbrel, golimumab, CNTO-148, simponi, certolizumab, certolizumab pegol, cdp870, cimzia, rituximab, anti-CD20, rituxan, mabthera, abatacept, ctla4 Ig, orencia, tocilizumab, atlizumab, actemra, roactemra, tofacitinib, xeljanz. No language restriction was used. Review articles were retrieved to identify additional references by hand search. For the purposes of simplicity of labelling, we shall designate all the primary drugs compared with MTX as biologics even though we realise that tofacitinib, developed to have biologic effects, is in fact a small molecule.

The following inclusion criteria were applied: RCT, RA, 18 years old or greater, biologic therapy in one group, MTX in one group, clinical outcome measures and study duration of at least 6 months and $\leq 24$ months. Articles that did not fulfil all the inclusion criteria, included MTX partial responders, used combined biologic drugs or presented only radiological outcomes, were excluded.

Studies were assessed by two independent investigators (JD and DD or $\mathrm{MB}$ ). Disagreements 
regarding study eligibility were resolved by discussion. Relevant articles were selected in a three-step procedure. First, titles were screened. When a title seemed relevant, the abstract was reviewed. Articles that addressed the topic of interest in the abstract were selected and reviewed in full paper.

\section{Data extraction}

Data extraction was performed by two independent investigators (JD and DD or MB) using a piloted form. Disagreements were resolved by discussion. From each study we collected the source (main author, journal, publication year), disease duration, former treatment, biologic used (route, combination with MTX), MTX dose and regimen, use of injectable placebo, time point of outcome, number of subjects, outcome measure, superiority of biologic reported $(\mathrm{y} / \mathrm{n})$ according to the conclusion presented in the paper, industry sponsorship and intention-to-treat analysis. If necessary, authors were contacted to provide additional information regarding MTX maximum dose. To evaluate the methodological quality of studies, the Cochrane risk of bias tool was used. ${ }^{6}$

\section{RESULTS}

A total of 3276 references were identified with the systematic search strategy after eliminating duplicates. Title screening left 414 abstracts for revision. After selecting abstracts, 75 articles/ conference abstracts were retrieved for full paper review. For our current study, 13 fulfilled the inclusion criteria (figure 1). Of these, three studied adalimumab, two infliximab, two etanercept, one golimumab, one abatacept, one rituximab, two tocilizumab and one tofacitinib (table 1). ${ }^{7-19}$ All but one study ${ }^{11}$ was sponsored by industry and in all industry-sponsored studies, the product of industrial sponsor was the biological agent.

Maximum dose of MTX was reported in 8 of the 13 trials. We were able to obtain additional information regarding MTX

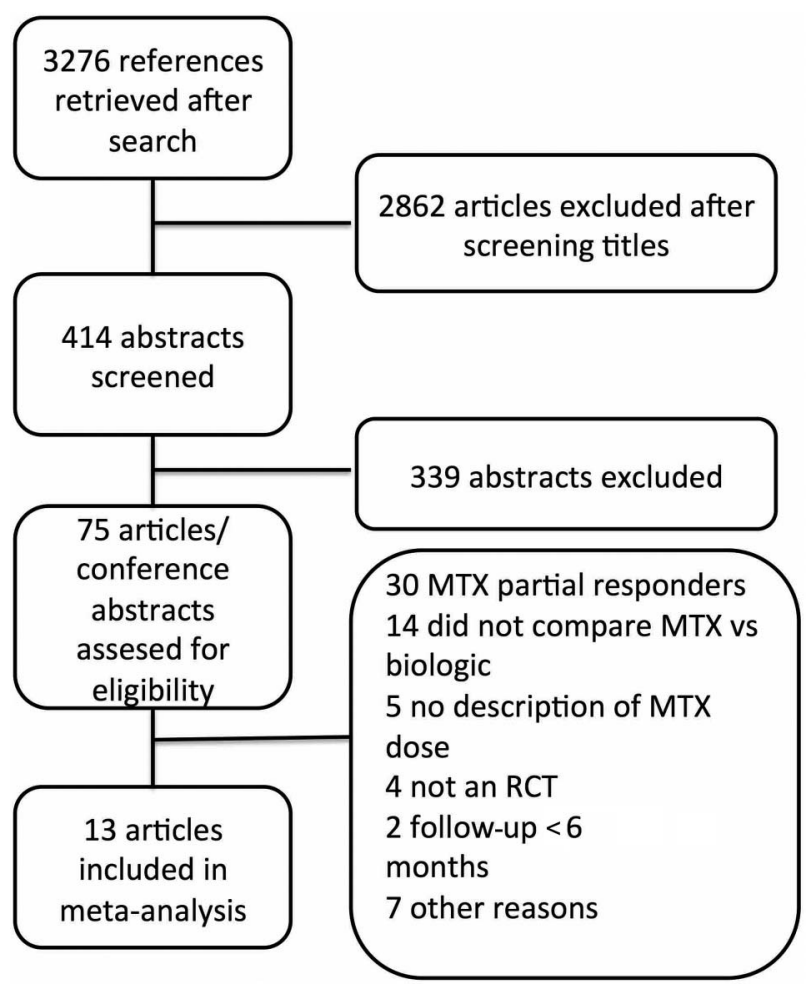

Figure 1 Flowchart of study selection process. doses for the remaining five studies. Overall, none of the studies used doses of more than $20 \mathrm{mg}$. Further, only one study allowed the use of injectable MTX and in this study the maximum dose was $15 \mathrm{mg} /$ week (table 2).

In all but two studies subjects received injected placebo. ${ }^{8} \quad 12$ Regarding clinical outcomes reported, with the exception of tocilizumab and tofacitinib studies, all trials reported no difference in efficacy. However, Bathon et $a l^{7}$ emphasised etanercept monotherapy had a quicker onset of action and was superior in radiological outcomes. All studies concluded that a combination of MTX with biologic drugs was superior to MTX monotherapy.

\section{Methodological quality of studies}

Details regarding internal validity of trials are presented in online supplementary table S1. None of them was considered at high risk of bias, but not all items were clearly reported in eight studies.

\section{DISCUSSION}

To our knowledge, this is the first systematic review that evaluates the dosage of the comparator MTX in biologic drug trials in RA. We found that in all trials in which there was a direct comparison with biologic drugs, MTX was not used at the maximum recommended dose. Moreover, injectable forms of MTX were only used in one of these trials, and in this trial it was not used at full dose.

A dose-effect relationship exists for MTX in RA treatment. Therefore, for it to be an appropriate comparator, the maximum dose should be used in subjects who require and tolerate it. Studies have shown that oral MTX has variable bioavailability between individuals and a decreasing relative bioavailability with increasing doses. Response to therapy is achieved only with maximum dose $(25-30 \mathrm{mg} /$ week) in a proportion of subjects, and there are no identified predictors that identify these patients. ${ }^{3}$ On the other hand, subcutaneous MTX has been shown to have a better bioavailability at high doses, and clinical studies support that it is more effective at an equal dose than oral MTX. As Schiff et $a l^{2}$ concluded recently in a cross-over study evaluating routes of administration in the same subject, drug-exposure limitations of oral MTX at doses $\geq 15 \mathrm{mg}$ may be overcome with subcutaneous administration.

Industry sponsorship bias has been documented by studies in different fields of medicine. ${ }^{1}$ A common theme in these studies has been the underdosing of the standard treatment comparator when a new drug is being tested. We suggest a similar phenomenon has occurred with the development of biologics in RA. Further, this suggests that the presumed superiority of some biologics either combined with MTX or as monotherapy over MTX may be overstated, given the suboptimal MTX regimens used. However, even though the superiority of parenteral higher dosing of MTX was known in the 1990s, ${ }^{20}$ before 2009 evidence regarding this benefit was scarce and most biologic trials were designed before this date. In addition, only recently has fast escalation of MTX up to $25 \mathrm{mg}$ been adopted widely and this may have influenced the early trials presented. Still, bias generated due to the use of suboptimal dose of MTX as a comparator that would favour biologics may lead to exposing patients to unnecessary risk or expense.

It may be argued that using injectable MTX in case of oral MTX failure would compromise blinding, but internal validity would probably not be harmed to an extent to justify not using the maximum effective dose. An alternative would have been the use of a study design like High Induction Therapy with 
Table 1 Summary of all included studies in the systematic review and the characteristics of patients

\begin{tabular}{|c|c|c|c|c|c|c|c|c|}
\hline Author (year) & Biologics & $\begin{array}{l}\text { Biologic branch-MTX } \\
\text { combination }\end{array}$ & $\begin{array}{l}\text { RA duration } \\
\text { (months) }\end{array}$ & $\begin{array}{l}\text { Total } \\
\text { subjects }\end{array}$ & $\begin{array}{l}\text { MTX } \\
\text { subjects }\end{array}$ & $\begin{array}{l}\text { Biologic } \\
\text { subjects* }\end{array}$ & $\begin{array}{l}\text { Main } \\
\text { outcomet }\end{array}$ & $\begin{array}{l}\text { Biologics reported } \\
\text { superior }\end{array}$ \\
\hline Bathon et al (2000) & ETN & Monotherapy & 12 & 632 & 217 & $208 / 207$ & ACR-N & $\mathrm{N} / \mathrm{Y}+$ \\
\hline Lee et al (2014) & TOFA & Monotherapy & 36 & 956 & 186 & $373 / 397$ & ACR70 & Y \\
\hline Breedveld et al (2006) & $\mathrm{ADA}$ & $\begin{array}{l}\text { Monotherapy } \\
\text { Combined }\end{array}$ & 8 & 799 & 257 & $\begin{array}{l}274 \\
268\end{array}$ & $\begin{array}{l}\text { ACR50 } \\
\text { mTSS }\end{array}$ & $\begin{array}{l}N \\
Y\end{array}$ \\
\hline Burmester et al (2015) & TCZ & $\begin{array}{l}\text { Monotherapy } \\
\text { Combined }\end{array}$ & 6 & 1157 & 287 & $\begin{array}{l}292 \\
291\end{array}$ & $\begin{array}{l}\text { DAS28 } \\
\text { Remission }\end{array}$ & $\begin{array}{l}Y \\
Y\end{array}$ \\
\hline Detert et al (2013)§ & $\mathrm{ADA}$ & Combined & 2 & 172 & 85 & 87 & DAS28 & Y \\
\hline Durez et al (2007) & INF & Combined & 4 & 44 & 14 & 15 & $M R I^{* *}$ & Y \\
\hline Emery et al (2008) & ETN & Combined & 10 & 528 & 263 & 268 & $\begin{array}{l}\text { DAS28 } \\
\text { remission } \\
\text { mTSS }\end{array}$ & Y \\
\hline Emery et al (2009) & GLM & $\begin{array}{l}\text { Monotherapy } \\
\text { Combined }\end{array}$ & 48 & 637 & 160 & $\begin{array}{l}159 \\
159 / 159\end{array}$ & ACR change & $\begin{array}{l}N \\
Y\end{array}$ \\
\hline Jones et al (2009)ף & TCZ & Monotherapy & 72 & 673 & 284 & 288 & ACR20 & Y \\
\hline Smolen et al (2014) & ADA & Combined & 3 & 1032 & 517 & 515 & DAS28 LDA & Y \\
\hline St Clair et al (2004) & INF & Combined & 11 & 1049 & 298 & 373 & ACR-N & Y \\
\hline Tak et al (2010) & RTX & Combined & 11 & 748 & 249 & 251 & mTSS & Y \\
\hline Westhovens et al (2009) & $A B A$ & Combined & 6 & 509 & 253 & 256 & $\begin{array}{l}\text { DAS28 } \\
\text { mTSS }\end{array}$ & Y \\
\hline
\end{tabular}

${ }^{*}$ Two numbers in a same trial correspond to different dose branches.

**MRI was the main outcome, but clinical outcomes including DAS28 and ACR response were reported.

tRegarding clinical outcomes all trials except Bathon et al reported DAS28 as one of their outcomes and all trials measured ACR response.

$\ddagger$ Activity scores were not superior at follow-up but the study conclusion states that the biological is beneficial due to more rapid effect and less radiological progression.

§Trial not sponsored by industry.

१There was also a branch that received placebo 12 weeks and then TCZ 12 weeks. It was not included due to the short follow-up using TCZ.

ABA, abatacept; ACR, American College of Rheumatology; ADA, adalimumab; Comb, combined therapy; CZP, certolizumab; DAS28, disease activity score 28; ETN, etanercept; GLM,

golimumab; INF, infliximab; inj, injectable; LDA, low disease activity; Mono, monotherapy; mTSS, modified total Sharp Score; MRI, magnetic resonance imaging; MTX, methotrexate; RA,

rheumatoid arthritis; RTX, rituximab; TCZ, tocilizumab; TOFA, tofacitinib.

Anti-Rheumatic Drugs (HIT HARD) in which only subcutaneous MTX was used to make sure everybody reached maximum levels of the drug without affecting blinding. ${ }^{11}$

Regarding the quality of studies, there was lack of reporting of important aspects in several trials, such as allocation concealment and blinding. Patient-reported and physician-reported outcomes used in activity scores may be affected by knowledge of the intervention.
Strengths of this study are that a comprehensive literature search was performed and no study was excluded due to language restrictions. In addition, authors were contacted when MTX dose/route was not clear and they all provided information about the MTX regimen used. A potential limitation is we did not perform a 'grey literature' search but 30 meta-analyses were hand searched and it is unlikely that studies were missed.

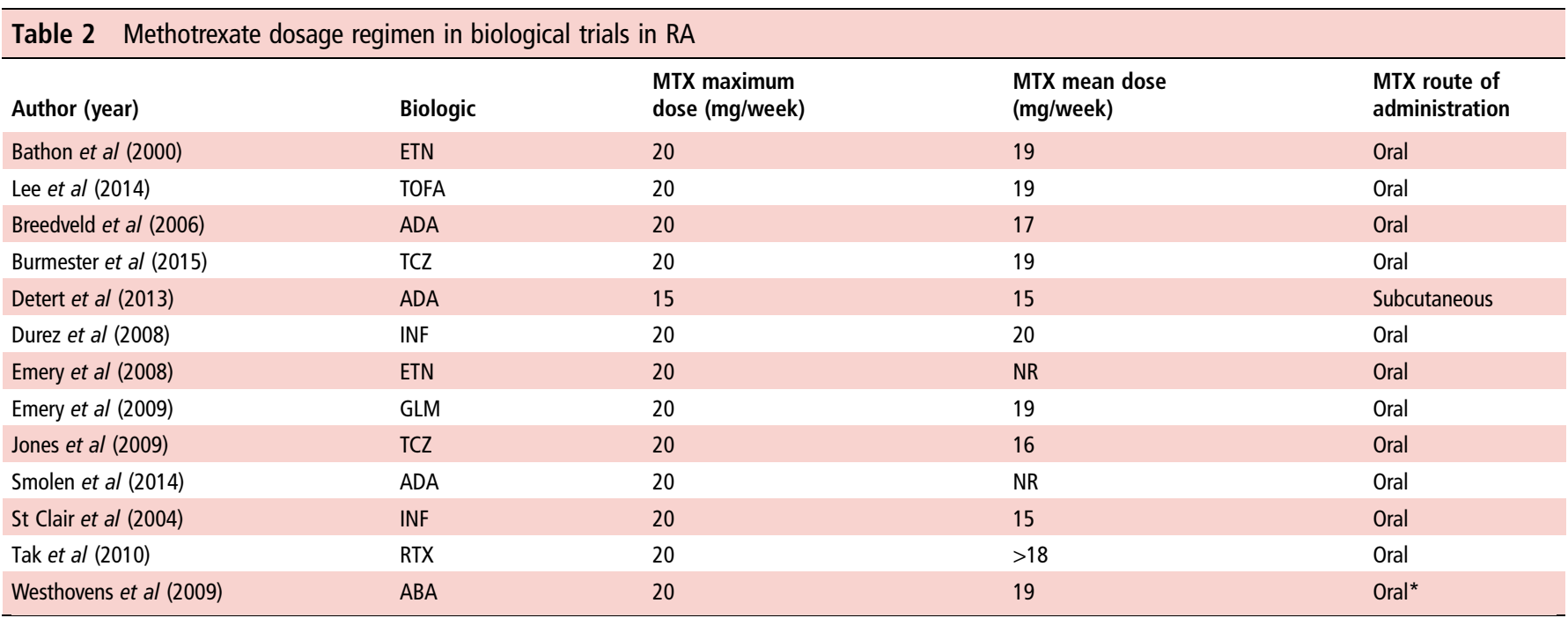

${ }^{*}$ In the Westhovens et al trial $1.5 \%$ of subjects received injectable MTX, but it was not part of the protocol.

ABA, abatacept; ADA, adalimumab; CZP, certolizumab; ETN, etanercept; GLM, golimumab; INF, infliximab; MTX, methotrexate; NR, not reported; RA, rheumatoid arthritis; RTX, rituximab; SC, subcutaneous; TCZ, tocilizumab; TOFA, tofacitinib. 


\section{CONCLUSION}

A suboptimal dose of MTX was used in biological drugs clinical trials performed in RA, particularly in relation to route of administration. This may have biased findings in favour of biologic agents in RA trials.

Acknowledgements We thank the researchers who kindly provided additional data from their studies: Josef S Smolen, Gerd R Burmester, Rene Westhovens, Eun Bong Lee and Patrick Durez.

Contributors All authors participated in drafting the manuscript or revising it critically for important intellectual content, and all authors approved the final version to be published. Study conception and design: JD, DF and ML. Acquisition, analysis and interpretation of data: JD, DF, DD and MB.

Funding This research study was supported by NIH AR47785.

Competing interests None declared.

Provenance and peer review Not commissioned; externally peer reviewed.

\section{REFERENCES}

1 Lundh A, Sismondo S, Lexchin J, et al. Industry sponsorship and research outcome. Cochrane Database of Syst Rev 2012;(12):MR000033.

2 Schiff MH, Jaffe JS, Freundlich B. Head-to-head, randomised, crossover study of oral versus subcutaneous methotrexate in patients with rheumatoid arthritis: drug-exposure limitations of oral methotrexate at doses $\geq 15 \mathrm{mg}$ may be overcome with subcutaneous administration. Ann Rheum Dis 2014;73:1549-51.

3 Braun J, Käestner P, Flaxenberg P, et al. Comparison of the clinical efficacy and safety of subcutaneous versus oral administration of methotrexate in patients with active rheumatoid arthritis: results of a six-month, multicenter, randomized, double-blind, controlled, phase IV trial. Arthritis Rheum 2008;58:73-81.

4 Smolen JS, Landewé $\mathrm{R}$, Breedveld $\mathrm{FC}$, et al. EULAR recommendations for the management of rheumatoid arthritis with synthetic and biological disease-modifying antirheumatic drugs: 2013 update. Ann Rheum Dis 2014;73:492-509.

5 Visser K, Katchamart W, Loza E, et al. Multinational evidence-based recommendations for the use of methotrexate in rheumatic disorders with a focus on rheumatoid arthritis: integrating systematic literature research and expert opinion of a broad international panel of rheumatologists in the $3 E$ Initiative. Ann Rheum Dis 2009;68:1086-93.

6 Higgins JPT, Altman DG, Gøtzsche PC, et al. The Cochrane Collaboration's tool for assessing risk of bias in randomised trials. BMJ 2011;343:d5928.

7 Bathon JM, Martin RW, Fleischmann RM, et al. A comparison of etanercept and methotrexate in patients with early rheumatoid arthritis. $N$ Engl I Med 2000;343:1586-93.

8 Lee EB, Fleischmann $R$, Hall $S$, et al. Tofacitinib versus methotrexate in rheumatoid arthritis. N Engl J Med 2014;370:2377-86.
9 Breedveld FC, Weisman MH, Kavanaugh AF, et al. The PREMIER study: a multicenter, randomized, double-blind clinical trial of combination therapy with adalimumab plus methotrexate versus methotrexate alone or adalimumab alone in patients with early, aggressive rheumatoid arthritis who had not had previous methotrexate treatment. Arthritis Rheum 2006;54:26-37.

10 Burmester GR, Rigby WF, van Vollenhoven RF, et al. Tocilizumab in early progressive rheumatoid arthritis: FUNCTION, a randomised controlled trial. Ann Rheum Dis 2016:75:1081-91.

11 Detert J, Bastian H, Listing J, et al. Induction therapy with adalimumab plus methotrexate for 24 weeks followed by methotrexate monotherapy up to week 48 versus methotrexate therapy alone for DMARD-naive patients with early rheumatoid arthritis: HIT HARD, an investigator-initiated study. Ann Rheum Dis 2013:72:844-50

12 Durez P, Malghem J, Nzeusseu Toukap A, et al. Treatment of early rheumatoid arthritis: a randomized magnetic resonance imaging study comparing the effects of methotrexate alone, methotrexate in combination with infliximab, and methotrexate in combination with intravenous pulse methylprednisolone. Arthritis Rheum 2007;56:3919-27.

13 Emery P, Fleischmann RM, Moreland LW, et al. Golimumab, a human anti-tumor necrosis factor $\alpha$ monoclonal antibody, injected subcutaneously every four weeks in methotrexate-naive patients with active rheumatoid arthritis: twenty-four-week results of a phase III, multicenter, randomized, double-blind, placebo-controlled study of golimumab before methotrexate as first-line therapy for early-onset rheumatoid arthritis. Arthritis Rheum 2009;60:2272-83.

14 Emery P, Breedveld FC, Hall S, et al. Comparison of methotrexate monotherapy with a combination of methotrexate and etanercept in active, early, moderate to severe rheumatoid arthritis (COMET): a randomised, double-blind, parallel treatment trial. Lancet 2008;372:375-82.

15 Jones G, Sebba A, Gu J, et al. Comparison of tocilizumab monotherapy versus methotrexate monotherapy in patients with moderate to severe rheumatoid arthritis: the AMBITION study. Ann Rheum Dis 2010;69:88-96.

16 Smolen JS, Emery P, Fleischmann R, et al. Adjustment of therapy in rheumatoid arthritis on the basis of achievement of stable low disease activity with adalimumab plus methotrexate or methotrexate alone: the randomised controlled OPTIMA trial. Lancet 2014;383:321-32.

17 St Clair EW, van der Heijde DM, Smolen JS, et al. Combination of infliximab and methotrexate therapy for early rheumatoid arthritis: a randomized, controlled trial. Arthritis Rheum 2004;50:3432-43.

18 Tak PP, Rigby WF, Rubbert-Roth A, et al., for the IMAGE Investigators. Inhibition of joint damage and improved clinical outcomes with rituximab plus methotrexate in early active rheumatoid arthritis: the IMAGE trial. Ann Rheum Dis 2011;70:39-46.

19 Westhovens R, Robles M, Ximenes AC, et al. Clinical efficacy and safety of abatacept in methotrexate-naive patients with early rheumatoid arthritis and poor prognostic factors. Ann Rheum Dis 2009;68:1870-7.

20 Weinblatt ME, Coblyn JS, Fox DA, et al. Efficacy of low-dose methotrexate in rheumatoid arthritis. N Engl J Med 1985;312:818-22. 